\title{
School science
}

VOL. I]

JANUARY, 1902.

[No. 8

\section{THE HELRISTIC METHOD OF TEACHING*}

BY HANRY E. ARMSTRONG.

"New times demand new measures and new men;
The world advances, and in time outgrows
The laws that in our fathers' days were best;
And, doubtless, after us some purer scheme
Will be sliaped out by wiser men than we,
Made wiser by the steady growth of truth."
"O * * *
"Onr time is onc that calls for earnest deeds."

(LOWELI.)

All who seriously study the history of education in our times must agree that, although it may be long ere we can cry Eureka! Eureka! of an ideally perfect system, recent experience justifies the assertion that we shall hasten the advent of that desirable time if we seek to minimize the didactic and encourage heuristic teaching; for the progress made of late, which is very considerable, is unquestionably due to the introduction of heuristic methods and exercises.

But many will ask-what are heuristic methods? Even the word is strange to us, they will add.

True it is not yet in the dictionary; but it is scarcely possible to doubt that it is come to stay, and will-nay, must-soon be there; indeed, its introduction as the watchword of a party seems really to meet a want.

\footnotetext{
* Parts of a Report to the Board of Education of England.
} 
Heuristic methods of teaching are methods which involve our placing students as far as possible in the attitude of the discoverer-methods which inyolve their finding out, instead of being merely told about things. It should not be necessary to justify such a policy in education. Unfortunately, however, our conceptions are blunted by carly training, or rather by want of training. Few realize that neither is discovery limited to those who explore Dark Continents or Polar Regions, nor to those who seek to unravel the wonders of Nature; that invention is not confined to those who take out patents for new devices; but that, on the contrary, discovery and invention are divine prerogatives, in some degree granted to all, meet for daily usage, and that it is consequently of importance that we be taught the rules of the game of discovery and learn to play it skillfully. The value of mere knowledge is immensely over-rated, and its possession over-praised and over-rewarded; action, although appreciated when its effects are noted, is treated as the outcome of innate faculties, and the extent to which it can be developed by teaching scarcely considered.

Professor Meiklejohn contends that the permanent and universal condition of all method in education is that it be heuristic; and goes on to say:

"This view has its historic side; and it will be found that the best way, the truest method, that the individual can follow is the path of research that has been taken and followed by whole races in past times. This has, perhaps, been best put by Edmund Burke, probably the greatest constructive thinker that ever lived in this country. He says: 'I am convinced that the method of teaching which approaches most nearly to the methods of investigation is incomparably the best; since not content with serving up a few barren and lifeless truths, it leads to the stock on which they grew; it tends to set the learner himself on the track of invention, and to direct him into those paths in which the author has made his own discoveries.' It may bé said, Professor Meikeljohn continues, that this statement is applicable to science and to science only." But I am prepared to show at the right time that it is applicable to literature also, though not in the fullest extent and application of the method. The heuristic method is the only method to be 
applied in the pure sciences; it is the best method in the teaching of the applied sciences; and as it is a method in the study of those great works of art in language by the greatest minds which go by the general name of literature.

It would be casy to support this contention by numerous other quotations, but one will suffice-than which, however, none could be more impressive or striking. I refer to the words used by Lessing: "If the Almighty were in the one hand to offer me Truth, and in the other the Search after Truth, I would humbly but firmly choose the Search after Truth."

I can clearly trace the development of my heuristic tendencies - which are certainly in a large measure innate, for my father was critical and enquiring-to one of my school books-absolutely the only interesting one that came into my hands- to a literary work, Trench's Study of Words; and can well recollect how this book at once fascinated me-and not me alone, but my father also, a commercial man, whose early training and career had been such as to leave him entirely unacquainted with subjects of the kind. I still vividly recall to mind how from this book, as a mere lad, I for the first time gained ideas as to the value of method-of what I should now call scientific method. It even taught me to appreciate Euclid, the deadly dullness of which subject long oppressed me, as it does probably almost every boy or girl at school, for there was no meaning apparent in it as it was presented; it seemed in no way to connect itself up with any experience I had gained; but somehow, after reading T'rench, the scales suddenly fell from my eyes, its logical character at least became evident, and it was no longer so difficult to understand or to master-but I cannot say that it ever became interesting or its use obvious. This experience has haunted me through life, and has often led me to think how much I might have learned at school had I bcen properly taught, or even provided with a few books giving insight into method, like Trench's; I owe to it more than to anything else the growth of a desire to promote the teaching of method.

As a student of science I was equally perverse. I had every desire to learn, but didactic teaching seemed always to produce 
a sense of irritation. Practical work was intensely interesting, although it was only too often done in obedience to orders without the underlying philosophical motive being clear. The facts recited in the lecture room, especially when accompanied by experimental illustrations, frequently came as revelations, but, on the whole, listening to lectures produced little abiding effect, one image following the other too quickly. Text books I always found unattractive and unsatisfying-often nauseating, for I felt that I wanted to become a chemical cook myself, not merely to know what the dishes were made of and what they looked like on the table; however, I got through them and the measles lightly, without any serious disturbance of mental balance, such as a hard fate, and unreflecting educators, impose on most students who are forced, by the pressure of examinations, to unduly indulge in food so indigestible and unpalatable. Happily the proper corrective was soon discovered; for, being an omnivorous reader, it was my good fortune, at an early stage, to have my attention called to original literature. Needless to say, this proved to be intensely interesting, as glimpses of method were soon gained from it. Full emancipation came later-the haven being reached when I passed from the mainly didactic surroundings of an English laboratory into the heuristic atmosphere of a German university. I seemed to escape into an Elysium.

Nevertheless, in the course of years, I had been insensibly compelled to swallow much poison, and this had its inevitable effect. Impressed habits and convictions were not easily cast aside; so that, when I started my career as a teacher, although I saw much reason to be dissatisfied with existing practices, it was only very gradually that I could divest myself of conventional articles of belief, or make up my mind what changes were necessary and feasible. Therefore I can always fully sympathize with teachers whose convictions have boen forced upon them-whose peace of mind was until recently undisturbed. It is easy to understand that it will be very difficult for them to enter fully into the spirit of the heuristic doctrines that are now being widely preached, and still more so for them to apply methods which they have never previously been trained to understand. 
It must from the outset and ever be remembered that the great object in view in education is to develop the power of initiative, and in all respects to form the character of the pupil. The appreciation of this contention is crucial. "The pious Pestalozzi is filled with measureless remorse when he finds that he has given a little boy a conception, instead of inducing him to find it himself," remarks Professor Meiklejohn. So should every teacher be; and if the feeling expressed in this sentence can but be made to rankle in the mind of every teacher, the end is achieved. Schools will then become educating institutions; the didactic instruction which poisons our existence at the present day will be properly recognized as a fell disease.

It is necessary to insist on this over and over again, as even among those who are becoming advocates of heuristic training there is often incomplete recognition of the fundamental importance of observing such an attitude towards learners. The following passage for example, occurs in the chapter headed "Physical Science" in Spencer's Aims and Practice of T'eaching Physical Science (London, $189 \%$, C. J. Clay \& Sons), to which I have contributed the chapter on chemistry.

"A great deal has been written in favor of the research attitude on the part of the learner. But despite the force of some of the arguments adduced, it may be doubted whether this attitude is the proper one for a beginner. At the commencement of a science course the teaching cannot be too simple, and it must be very clear and definite. Each step taken should logically follow from the work already done, and every experiment should be undertaken with a definite object, which should be fully under. stood and appreciated by the class. In working out a course of this kind, the teacher might, with advantage, follow an imaginary research path into the subject, but the scholars may not become conscions of this, and it is quite unnecessary that they should. If scholars are taught to obserye. the progress of an experiment in a vague sort of way, and asked to deduce results from their observations, without being told definitely what to look for and how to look for it, the only result of the work is waste of time. In fact, until the scholars have acquired a little knowledge of the subject, it is uselcss to expect them to reason for themselves in the way necessary to follow out even the simplest research. Reasoning of this kind involves a knowledge of the facts and 
principles of the subjects, and a beginner's time is best employed in acquiring this knowledge under the guidance of a competent teacher?"”

This presentment of the question may appeal to some who are not versed in the work. It is no question, however, of force of arguments adduced, but one of facts established, and of experience gained in practice among scholars of every type. It is in no sense mere opinion on my part, but a conviction gradually forced upon me and established beyond all doubt by actual trial and observation during many years past, that the beginner not only may but must be put absolutely in the position of an original discoverer; and all who properly study the question practically are coming to the same opinion, I find. Young children are delighted to be so regarded; to be told that they are to act as a band of young detectives. For example, in studying the rusting of iron, they at once fall in with the idea that a crime, as it were, is committed when the valuable, strong iron is changed into useless, brittle rust, and with the greatest interest set about finding out whether it is a case of murder or of suicide, as it werewhether something outside the iron is concerned in the change, or whether it changes of its own accord.

It is of no use for the teacher merely to follow an imaginary research path; the object must ever be to train children to work out problems themselves, and to acquire the utmost facility in doing so. Of course, the problems must be carefully graduated to the powers of the scholars, and they must be insensibly led; but do not let us spoil them by telling them definitely in advance what to look for and how to look for it; such action is simply criminal.

My experience teaches me also that it is the grossest libel on young scholars to say that it is useless to expect them to reason for themselves in the way necessary to follow out the simplest research; but, unfortunately, if you substitute teachers for scholars this is too often a true statement, and here the supreme difficulty of properly carrying out heuristic teaching comes in. It is the teachers who are preventing advance. Let us teachers recognize this; but do not let us overwork and misrate the powers of young children. 
Let us try what we can do, and if we do not at first succeed, let us try and try again; we shall surely succeed if we can only adopt this attitude. But, if we fail, let us give up the work as-soon as possible, and leave it to others to succed where we have failed. No other policy is an honest one-for the teaching of young children should never be regarded as a perfunctory: task, but as a sacred office. The whole policy of the teacher's duty is summed up in one little word, yet the most expressive in the English language: it is to train pupils to do. On this it is easy to base a simple test of competency.

It is needless to say young scholars cannot be expected to find out everything themselves; but the facts must always be so presented to them that the process by which results are obtained is made sufficiently clear, as well as the methods by which any conclusions based on the facts are deduced. And before didactic teaching is entered upon to any considerable extent, a thorough course of heuristic training must have been gone through in order that a full understanding of the method may have been arrived at, and the power of using it acquired; scientific habits of mind, scientific ways of working, must become ingrained habits from which it is impossible to escape. As a necessary corollary, subjects must be taught in such an order that those which can be treated heuristically shall be mainly attended to in the first instance.

\section{PROFESSOR MORLEY ON THE TEACHING OF CHEM- ISTRY.}

BY LYMAN O. NEWELL.

At a recent meeting of secondary school teachers, Professor Edward W. Morley, of Western Reserve University, made some remarks on "The Teaching of Chemistry." As far as the writer knows, this paper has been published in only one magazine, and 